\title{
Crianças com dificuldades motoras: questões para a conceituação do transtorno do desenvolvimento da coordenação
}

\author{
Luis Eduardo Bastos Pinto Tourinho Dantas * \\ Edison de Jesus Manoel ${ }^{*}$
}

\begin{abstract}
Resumo: A investigação da natureza das dificuldades motoras experimentadas por crianças resultou na identificação do Transtorno do Desenvolvimento da Coordenação (TDC). Pouco se sabe sobre sua natureza, embora sejam inúmeras as hipóteses formuladas sobre sua causa. O presente artigo defende a tese de que o problema reside na definição do que se entende por TDC e na seleção de amostras em estudos que não distinguem o uso de critérios clínicos dos critérios de pesquisa. Em conclusão, são apresentadas três etapas para caracterização do TDC.
\end{abstract}

Palavras-chave: Transtornos das habilidades motoras. Crianças. Deficiências do desenvolvimento.

"Muitas teorias haviam sido formuladas para explicar a doença, confirmando o velho aforismo médico segundo o qual a abundância de hipóteses é sinônimo de ignorância."

Synclair, M.p.12

\section{INTRODUÇÃo}

Para muitos, quando se pensa em movimentos corporais, logo vem à mente a figura de indivíduos altamente habilidosos realizando atividades motoras de forma excepcional como profissionais da dança e do esporte. Todavia, a característica mais marcante do movimentar-se

* Líder do Grupo de Estudo do Desenvolvimento da Ação e Intervenção Motora da USP, Professor Doutor da USP. Escola de Educação Física e Esporte. Universidade de São Paulo. São Paulo, SP, Brasil. E-mail: Idantas@usp.br

**Líder do Grupo de Estudo do Desenvolvimento da Ação e Intervenção Motora da USP Professor Titular da USP. E-mail: ejmanoel@usp.br 
humano não é a sua excepcionalidade, mas sua ubiquidade. A grande maioria da população é capaz de executar inúmeros movimentos com relativa competência na realização de atividades do cotidiano. Essas atividades vão desde se vestir, se alimentar, até ocupacionais (dirigir um carro, digitar em computadores e máquinas registradoras etc.) e de lazer (jogar, caminhar em trilhas etc.). Várias dessas atividades são adquiridas com pouca ou nenhuma instrução formal.

Diante dessa ubiquidade, chamou a atenção da comunidade médica e acadêmica o fato de alguns indivíduos, crianças em particular, apresentarem extrema dificuldade para realizar essas atividades cotidianas. Indivíduos com essas dificuldades mostram-se muito defasados em relação às competências motoras da maioria da população, considerando não só o desempenho esperado para cada faixa etária. Ao mesmo tempo, eles não apresentam sinais neurológicos clássicos e sua condição é resistente a intervenções rotineiras. Essa condição é caracterizada por problemas na organização e produção de movimentos e as causas de tais problemas são, no momento, desconhecidas. Por essa razão, a comunidade acadêmica e profissional (educadores físicos, médicos, fisioterapeutas, terapeutas ocupacionais) reconhece, desde a década de 1980, que há um transtorno predominantemente motor e que o mesmo afeta de forma negativa o desenvolvimento global do indivíduo. Essa condição tem sido nomeada como Transtorno do Desenvolvimento da Coordenação (TDC) pela Associação Psiquiátrica Americana (DSM) - IV (2002) e Transtorno específico do desenvolvimento motor, pela Organização Mundial da Saúde (OMS) CID-10 (1993).

Apesar dos inúmeros esforços de pesquisa para explicar e intervir nesse problema, o avanço, em ambos os casos, não tem sido animador. Existem muito mais hipóteses explicativas do que seria razoável, e o esforço para remediar o problema via intervenção, não têm, na maior parte das vezes, tido o sucesso esperado. Os motivos dessa situação, em ambas as frentes (pesquisa e remediação), tem sido atribuídos à heterogeneidade dessa população. Entretanto, há outra causa ainda pouco explorada que diz respeito aos critérios de classificação ou categorização adotados para nomear as crianças com dificuldades motoras. Esses critérios, originalmente criados para fins clínicos,

Movimento, Porto Alegre, v. 15, n. 03, p. 293-313, julho/setembro de 2009. 
não seriam adequados para a finalidade de pesquisa, principalmente no que concerne à formação de grupos experimentais. Como consequência, a seleção de grupos experimentais teria grande variabilidade interna. Isto limitaria a interpretação, comparação e gene-ralização dos resultados de pesquisa acumulados. Logo, a heterogeneidade atribuída ao TDC (condição) pode, na verdade, residir nos critérios de categorização para identificação da mesma. O presente ensaio tem como propósito apresentar a tese de que o Transtorno do Desenvolvimento da Coordenação carece de critérios válidos para sua definição com fins de pesquisa, o que repercute negativamente nas investigações acerca da natureza desse transtorno e no desenvolvimento dos métodos de intervenção.

\section{NASCIMENTO DE UM TRANSTORNO DO DESENVOLVIMENTO}

$\mathrm{O}$ interesse por crianças que exibem dificuldades motoras possui uma história antiga e diversa. Desde o início do século passado, pesquisadores oriundos de um amplo espectro de campos de conhecimento e atuação profissional, abrangendo desde a Educação Física até a Medicina e a Psicologia, têm destacado e investigado problemas motores em crianças.

Hulme e Lord (1986) revisaram duas referências ao fenômeno ainda na primeira metade do século passado. Primeiramente Collier, ${ }^{1}$ no início do século XX, cunhou o termo congenitally maladroit para se referir a um grupo particular de crianças que manifestavam marcantes dificuldades motoras, sem apresentar, no entanto, uma causa conhecida. Segundo Orton (1937), que relatou a existência de algumas crianças que demonstram um desajeitamento motor (comprometimento nas habilidades locomotoras e de manipulação de objetos) na ausência de qualquer condição neurológica.

As consequências de ser portador dessa condição também já eram aventadas, ao menos empiricamente, desde o início do século XX. Vale destacar a descrição que Elias Canneti (1935, p.155) faz

${ }^{1}$ Fonte não revelada

Movimento, Porto Alegre, v. 15, n. 03, p. 293-313, julho/setembro de 2009. 
do personagem Kien, em seu livro Die Blendung (Auto de Fé, na tradução brasileira):

\begin{abstract}
Ao fim da metade da hora da visita, Kien gemia de dores antigas, aparentemente esquecidas. Desde a infância, jamais tivera firmeza nas pernas. No fundo, nunca aprendera a andar corretamente. Na aula de ginástica caía da barra fixa. A despeito do comprimento das pernas, era o pior corredor do curso. Para os professores, a debilidade física do menino simplesmente contrariava a natureza. Em todas as matérias, Kien era o melhor da turma, graças a sua excelente memória. Mas do que adianta isso? $\mathrm{Na}$ realidade devido a seu corpo ridículo, ninguém o respeitava. Davam-lhe inúmeras rasteiras que, invariavelmente, o faziam tropeçar. No inverno transformavam-no em boneco de neve, até que seu corpo adquirisse a grossura normal.
\end{abstract}

Em dezembro de 1962, o British Medical Journal dedicou seu editorial à discussão das origens ou causas das dificuldades motoras que algumas crianças enfrentavam no contexto escolar. Naquela comunicação, levantou-se a hipótese de que esses problemas teriam como causa uma condição médica primária. $\mathrm{O}$ editorial destaca quatro trabalhos independentes que sugerem a existência de uma síndrome de causa desconhecida. Segundo esse documento, Annell (1951; 1959), na Suécia, vinha descrevendo um grupo de crianças consideradas motoramente desajeitadas. Eram caracterizadas como inábeis no desempenho de movimentos funcionais (particularmente na escrita), no desempenho em jogos e atividades físicas e, além disso, manifestavam dificuldade em concentrar-se. Com relação à natureza e prognóstico do problema, Annell especulava que esse era de natureza maturacional e que a recuperação seria espontânea. Infelizmente, atualmente sabe-se que essa hipótese não se confirmou. Da Holanda, foi citado um relato de Prechtl e Stmmer (1962), no qual eram descritas um grupo de crianças desajeitadas. Novamente, somado a uma dificuldade de concentração, as crianças exibiam uma série de dificuldades motoras. O editorial cita também um trabalho advindo do próprio Reino Unido. Nessa pesquisa, Walton, Wellis e Court, em 1962, descreviam um grupo de cinco crianças desajeitadas

Movimento, Porto Alegre, v. 15, n. 03, p. 293-313, julho/setembro de 2009. 
motoramente. Os autores examinaram cuidadosamente esse grupo e destacaram: a dificuldade em executar inúmeras ações motoras cotidianas (alimentar-se, vestir-se, andar etc), assim como problemas perceptivo-motores: dificuldade em tarefas de encaixe, em tarefas de cópia de formas simples, em tarefas que envolvem timing coincidente (agarrar uma bola), entre outras. O editorial destaca ainda uma conferência sobre neurologia infantil, promovida pela Spastics National Society, em 1962, na qual Illingworth ${ }^{2}$ descreveu (e também mostrou um filme) um grupo de crianças encaminhadas para ajuda médica por exibirem marcantes dificuldades motoras, apesar de contrastantes sinais de normalidade (andar normal, quociente de inteligência normal ou acima do normal). Na conclusão, o editorial deixa claro uma preocupação com o reconhecimento dessa síndrome no meio médico e educacional, sugerindo a necessidade premente de estudos voltados para essa população.

Atualmente, esse problema é reconhecido na bibliografia médica e está classificado nos seus dois principais sistemas de referência. Segundo a APA - DSM - IV (2002, p. 88), o TDC é diagnosticado quando:

Critério A. O desempenho em atividades diárias que exigem coordenação motora está substancialmente abaixo do nível esperado, considerando a idade cronológica e a inteligência medida do indivíduo. $\mathrm{O}$ quadro pode manifestar-se por atrasos marcantes em alcançar marcos motores (por ex., caminhar, engatinhar, sentar), propensão a deixar cair coisas, desajeitamento, fraco desempenho nos esportes ou caligrafia insatisfatória.

Critério B. A perturbação do Critério A interfere significativamente no rendimento escolar ou nas atividades da vida diária.

Critério C. A perturbação não se deve a uma condição médica geral, por exemplo, paralisia cerebral, hemiplegia ou distrofia muscular, nem satisfaz os critérios para um Transtorno Invasivo do Desenvolvimento.

2 Fonte não revelada

Movimento, Porto Alegre, v. 15, n. 03, p. 293-313, julho/setembro de 2009. 
Critério D. Em presença de Retardo Mental, as dificuldades motoras excedem aquelas associadas com esse transtorno.

O termo transtorno é sugerido como uma forma de distinguir esse tipo de condição médica de doença para evitar problemas ainda maiores advindos do uso das expressões como "doença" ou "enfermidade" (OMS, 1993). A OMS reconhece que não é um termo exato, porém aponta para a existência de um conjunto de sintomas ou comportamentos clinicamente reconhecíveis, associados, na maioria dos casos, às dificuldades marcantes no desempenho de atividades motoras cotidianas, ocupacionais e recreativas.

Já o termo desenvolvimento, indica que o problema se manifesta nas fases iniciais da aquisição de ações motoras, vindo a interferir em todo processo de desenvolvimento subsequente, isto é, na contínua especialização e diversificação dessas ações (RISPEN; VAN YPEREN, 1998).

O termo coordenação é colocado para denotar o cerne do transtorno, isto é, ele busca explicitar a dificuldade de organizar e realizar ações motoras. Coordenação, por sua vez, pode ser vista como a capacidade de exercer controle sobre múltiplas relações que se estabelecem entre os elementos que compõem o sistema motor. Para Bernstein (1996), o controle do sistema motor do corpo é um problema complexo, multifacetado que, mesmo em sua versão mais limitada, não pode ser resolvido pela mais sofisticada tecnologia atualmente existente. Esse problema ficou conhecido com o problema dos graus de liberdade. Segundo Bernstein (1996, p. 41): "Coordenação é dominar o excessivo números de graus de liberdade do aparelho locomotor, isto é, fazê-lo um sistema controlável." (tradução dos autores)

No caso específico do TDC, o termo denota existir um problema no desenvolvimento dessa capacidade, o que dificultaria à contínua reordenação dos elementos que compõem o sistema motor, nos níveis intra-articular, intramembros e intermembros. Os indivíduos portadores desse transtorno não se caracterizam pela manifestação de comportamentos des/coordenados (sem coordenação), mas sim por um problema na regulação ou controle da coordenação, considerando-se as

Movimento, Porto Alegre, v. 15, n. 03, p. 293-313, julho/setembro de 2009. 
restrições ambientais, do organismo, e da própria ação motora. Um ponto que lança dúvidas sobre o TDC é o de que se assume que há um problema no desenvolvimento sem que de fato o mesmo tenha sido constatado. Presume-se que há tal transtorno porque o comportamento esperado da criança fica muito aquém do esperado para a sua idade. Isto é, usa-se de uma lógica normativa para dizer que o que não se encaixa na norma é "anormal", isto é, com "transtorno". São raros os estudos longitudinais com crianças portadoras do TDC. Assim, não é possível saber se as dificuldades de coordenação surgem porque o seu desenvolvimento foi afetado ou porque ao ter problemas de coordenação o desenvolvimento motor é prejudicado, o que viria a causar ainda mais problemas de coordenação num mecanismo de retroalimentação positiva.

O avanço na compreensão de qualquer fenômeno passa pela formulação de três perguntas: O que é? Por que é? Quais são as possibilidades? (LACEY, 1998). Aplicando-se esses questionamentos para o estudo do TDC, a primeira pergunta refere-se a questões de caracterização e identificação do transtorno; a segunda refere-se à sua natureza, e a terceira tem seu foco no seu desenvolvimento e intervenção. A relação entre a definição do objeto (neste caso, o transtorno), a explicação da sua natureza e as possibilidades de intervenção é direta, como o mesmo Lacey $(1998$, p. 16) afirma: "Dependendo como o objeto é considerado, as respostas às perguntas - por que é? e o que é possível? - tomam formas diferentes e refletem interesses diferentes."

Ao seguir o raciocínio lógico proposto por Lacey, depara-se com algumas dificuldades para se caracterizar o transtorno do ponto de vista conceitual e teórico. Nesse sentido, cabe destacar alguns pontos que Hopkins (2005) considera como nebulosos na caracterização de transtornos do desenvolvimento. Um refere-se à noção de "desenvolvimento normal" que variou ao longo do tempo e é diferente entre culturas. Outro ponto concerne à demarcação entre desenvolvimento sem transtorno e com transtorno, que é feita com base em indicadores falíveis de desvios estabelecidos a partir de um conjunto de normas idealizado e arbitrário. Não bastassem esses pontos, no caso específico do TDC, Hopkins ainda cita dois problemas: primeiro, a comorbidade

Movimento, Porto Alegre, v. 15, n. 03, p. 293-313, julho/setembro de 2009. 
do transtorno (ele geralmente vem acompanhado de outros transtornos). Segundo, sua descrição se centraliza em características comuns independentes da idade. No segundo caso, a desconsideração da idade implica negligenciar a passagem do tempo e as mudanças que se associam a essa passagem tornando "não desenvolvimentista" a empreitada de identificação do transtorno. Mas há ainda outros pontos que passamos a tratar na sequência.

\section{MAL USO DE UMA DEFINIÇÃo}

A categorização do TDC e as possibilidades de uso dessa categorização são temas nem sempre considerados pelos pesquisadores focados nesse problema. Para fins de pesquisa, particularmente, na seleção de sujeitos para composição de grupo experimental, os critérios para identificação dessa condição médica (representados tanto na CID-10 da OMS como no DSM-IV da APA) não são satisfatórios. Cermark, Gubbay e Larkin (2002, p. 7) ilustram bem a finalidade e o alcance original da categoria TDC:

TDC pode ser visto como termo temporário que
profissionais e pesquisadores irão usar até alcançarem
uma compreensão mais profunda dessa complicada
condição. As vantagens do uso desse termo são de
ordem mais prática que teórica. Ele não carrega uma
controvérsia histórica, como por exemplo, dispraxia,
nem supõe implicitamente uma etiologia, como o faz
"disfunção cerebral mínima". Existe uma conseqüên-
cia prática do reconhecimento e critério de diagnós-
tico fornecido pela APA (1987,1994). Em países onde
existem sistema de saúde pública, crianças diagnos-
ticadas com TDC podem se candidatar a receber
recursos financeiros governamentais para financiar
assistência terapêutica (tradução dos autores).

Mais a frente, no mesmo trabalho, Cermark, Gubbay e Larkin (2002, p. 22) afirmam:

Transtorno do desenvolvimento da coordenação é um termo obscuro sem uma definição precisa. Ele serve para definir um largo espectro de problemas motores moderados que pesquisadores e profissionais lutam para refinar (tradução dos autores)

Movimento, Porto Alegre, v. 15, n. 03, p. 293-313, julho/setembro de 2009. 
Os critérios adotados para um diagnóstico de TDC têm sido úteis para o reconhecimento dessa condição, para a organização de um esforço multidisciplinar de investigação do fenômeno (a criação da Sociedade Internacional para Pesquisa de TDC é um exemplo) e comunicação entre os pesquisadores. Mas pode ser considerado um obstáculo à construção e validação de instrumentos de identificação, compreensão da causa, ou causas, do TDC, comparação e generalização dos resultados e, até mesmo, para busca de soluções terapêuticas para esse tipo de transtorno do desenvolvimento. Antes de avançar na análise dessa tese, precisa-se destacar alguns aspectos do processo de categorizar ou classificar objetos.

A capacidade de classificar objetos em categorias é uma característica básica do cérebro e refere-se ao processo de agrupar objetos dentro de uma representação genérica. Isso pressupõe algum propósito, e também, critérios em torno dos quais os objetos são agrupados.

As investigações, por parte da psicologia cognitiva sobre o fenômeno da categorização, têm apontado para, ao menos, duas formas de classificar objetos (HAHN; CHARTER, 1997). A primeira está baseada no princípio da similaridade. Isso quer dizer que categorizar um objeto envolve julgar a similaridade entre ele e um outro objeto exemplar (protótipo), ou um conjunto de objetos exemplares. Uma segunda forma de construir categorias não faz referência direta ao princípio de similaridade, se baseia em definições ou pressupostos teóricos. Ela é chamada de visão clássica, e assume que toda categoria é definida por um conjunto de características ou propriedades, necessárias e suficientes (LAMBERTS; SHANKS, 1997). O processo de classificar pode ser descrito como uma investigação sobre um objeto, procurando determinar se o mesmo apresenta as características consideradas necessárias e suficientes, para pertencer à categoria X. Os manuais CID-10 (OMS, 1993) e DSM-IV (APA, 2002) procuram seguir essa segunda estratégia de classificação, nomeada como clássica, mas com fins clínicos e não de pesquisa.

Para ciência, a classificação de objetos tem três finalidades principais: Organização, de uma forma que elimine a necessidade da aplicação de modelos e conceitos para objetos específicos, o que,

Movimento, Porto Alegre, v. 15, n. 03, p. 293-313, julho/setembro de 2009. 
em face da imensa variedade de objetos existentes, em qualquer campo, é uma necessidade crítica; Generalização, de maneira que se possa identificar uma unidade em objetos aparentemente diferentes, isso dá margem para a construção de teorias e dedução de leis que se aplicam a uma ampla gama de fenômenos; Aplicação para que o conhecimento produzido seja válido perante a natureza dos objetos, dando margem ao desenvolvimento de processos de mudança da realidade a partir desse conhecimento.

O grau de sucesso em atingir essas finalidades depende diretamente da maturidade da categorização e da compreensão por parte do pesquisador dos limites do sistema de classificação que utiliza. Uma categoria não é algo estático, que uma vez definida permanece imutável. A partir de sua determinação inicial, muitas vezes baseada em critérios vagos e superficiais, pode-se iniciar um processo de investigação científica que, como consequência, poderá modificar os critérios inicialmente estabelecidos, e tornando a categoria cada vez mais válida e funcional.

Como viu-se anteriormente, a finalidade para a qual é proposto o sistema de classificação tem de ser considerada, e, na área médica, isso implica uma distinção entre finalidade de pesquisa e finalidade clínica. Para fins de pesquisa, opta-se pelos extremos de qualquer distribuição, com pouca ou nenhuma preocupação pela limitação em termos de exemplares da categoria. Em outras palavras, busca-se tornar a categoria a mais restrita possível, isto é, com o maior grau de homogeneidade possível. Por outro lado, para fins clínicos, as considerações práticas podem ter prioridades sobre considerações científicas. A óptica da classificação clínica é a orientação para intervenção, ou atendimento da população. Assim, uma categoria com finalidade clínica almeja abranger todos os exemplares, a preocupação com a questão da homogeneidade é secundária.

Para o estudo científico de qualquer comportamento, um grande passo é categorizar (abordagem clássica) esse comportamento. Somente a partir de sua determinação como categoria, poder-se-á abordálo experimentalmente, isto é, manipulá-lo para tentar explicar sua natureza e sua dinâmica. Poder-se-á cometer equívocos investigando o

Movimento, Porto Alegre, v. 15, n. 03, p. 293-313, julho/setembro de 2009. 
TDC a partir de critérios obscuros e vagos. Postular mecanismos, especular causas, sem antes construir uma definição restrita do fenômeno, é pouco produtivo para compreensão do referido transtorno. Nessas condições, a comunicação entre os pesquisadores, em vez de facilitada, será comprometida; e a generalização dos resultados, em vez de ser ampliada, será fonte de controvérsias e confusões. Assim, pode ser que o "tímido" progresso na compreensão e intervenção do TDC, seja devido ao descompasso que se dá em usar um sistema de classificação com fins clínicos para fins de pesquisa.

Há um reconhecimento de que parte das dificuldades encontradas na investigação e intervenção em transtornos que os indivíduos apresentam deve-se à imprecisão dos conceitos associados à deficiência (AMIRALIAN; PINTO; GHIRARDI; LICHTIG; MASINI; PASQUALIN, 2000). A compreensão da natureza de um transtorno pode se beneficiar da análise de três conceitos oriundos de classificações da OMS como a contida no International Classification of Impairments, Disabilities and Handicap: deficiência (impairment), incapacidade (disability) e desvantagem (handicap). Amiralian et al., 2000, com base nessa classificação, apresentam as seguintes definições:

Deficiência: perda ou anormalidade de estrutura ou função psicológica, fisiológica ou anatômica, temporária ou permanente. Incluem-se nessas a ocorrência de uma anomalia, defeito ou perda de um membro, órgão, tecido ou qualquer outra estrutura do corpo, inclusive das funções mentais. Representa a exteriorização de um estado patológico, refletindo um distúrbio orgânico, uma perturbação no órgão.

Incapacidade: restrição, resultante de uma deficiência, da habilidade para desempenhar uma atividade considerada normal para o ser humano. Surge como conseqüência direta ou é resposta do indivíduo a uma deficiência psicológica, física, sensorial ou outra. Representa a objetivação da deficiência e reflete os distúrbios da própria pessoa, nas atividades e comportamentos essenciais à vida diária.

Desvantagem: prejuízo para o indivíduo, resultante de uma deficiência ou uma incapacidade, que limita

Movimento, Porto Alegre, v. 15, n. 03, p. 293-313, julho/setembro de 2009. 


\begin{abstract}
ou impede o desempenho de papéis de acordo com a idade, sexo, fatores sociais e culturais. Caracterizase por uma discordância entre a capacidade individual de realização e as expectativas do indivíduo ou do seu grupo social. Representa a socialização da deficiência e relaciona-se às dificuldades nas habilidades de sobrevivência. (AMARALIAN et al., 2000, p 98).
\end{abstract}

A deficiência sempre refere-se a alguma condição ou dimensão como deficiência de visão ou de audição. A incapacidade caracteriza-se pela limitação em fazer algo, por exemplo, ver ou falar. A desvantagem manifesta-se em função de características do meio físico e social que podem dificultar ou possibilitar ao indivíduo agir em seu meio. Por exemplo, o meio físico pode diminuir a desvantagem de um deficiente visual quando, no piso pelo qual ele se desloca, há presença de marcas e variações físicas que lhe permitem localizar-se no espaço. Já o meio social pode aumentar a desvantagem de um indivíduo com deficiência de audição quando ele convive com pessoas que não dominam a linguagem de sinais. No caso do TDC, a incapacidade e a desvantagem têm sido amplamente descritas (LOSSE; HENDERSON; ELLIMAN; HALL; KNIGHT; JONGAMANS, 1991), entretanto, a caracterização da deficiência ainda é matéria de debate.

Sugere-se que, em futuros trabalhos, a identificação dos indivíduos com TDC, para fins de pesquisa, seja feita em três etapas. As duas etapas iniciais já foram propostas por Wright e Sugden (1996). Nesse trabalho, os autores levantam a existência de dois critérios consensuais para a identificação do TDC, ambos sugeridos tanto pela OMS (1993) quanto pela APA (2002) em seus manuais (clíni$\cos )$. Um critério é que a criança claramente demonstre um desempenho distante das normas reconhecidas para sua idade cronológica (atraso no alcance dos marcos motores). Essa condição deve ser avaliada por testes padronizados normativos. Outro critério destaca que a dificuldade observada tenha um impacto negativo na vida cotidiana da criança, o que corresponde à condição de um transtorno.

Apesar de não ser o foco deste trabalho, vale destacar que a verificação desse segundo critério, o impacto da dificuldade motora

Movimento, Porto Alegre, v. 15, n. 03, p. 293-313, julho/setembro de 2009. 
sobre a vida da criança, não vem sendo feita na maioria dos trabalhos publicados sobre essa temática (GEUZE; JONGMANS; SCHOEMAKER; SMITS-ENGELSMAN, 2001). Pode-se especular que isso seja devido a conceito de saúde adotado pelos pesquisadores da área médica. O conceito de saúde adotado é sinônimo de normalidade funcional. Assim a saúde é vista e medida exclusivamente com base em média estatística (no TDC, escores médios em testes motores).

Dessa forma, confunde-se diferença com patologia. Se nomeasse toda e qualquer anomalia como patológica, ter-se-ia que considerar doentes atletas (alterações fisiológicas), músicos (alterações morfológicas no cérebro) etc. A visão de saúde que está suportando o conceito de transtorno é outra, como explicita Caponi (2003):

Não são as médias estatísticas nem as fugas dos
intervalos assim chamados de normais, que nos indi-
cam o momento em que se inicia um transtorno,
mas sim as dificuldades que o organismo encontra
para dar respostas às demandas que seu ambiente
lhe impõe. (CAPONI, 2003, p.118)

Assim, para ser identificado como portador de TDC, os desvios da média não são suficientes. É necessário que o sujeito explicite o sofrimento causado pelas dificuldades de encontrar respostas às demandas que seu ambiente lhe impõe, e seja observado o impacto dessa dificuldade na sua vida cotidiana. Vale ressaltar que esses julgamentos acabam por se basear no que constitui a normalidade para um dado grupo de indivíduos. Como é destacado por Hopkins (2005), o conceito de normalidade pode ser resultado de várias interpretações. Hopkins (2005) destaca quatro noções a partir do trabalho de Offer e Sabshin (1974) normalidade como média (a interpretação mais comum) a partir de desempenhos relativos a padrões etários normativos; normalidade como saúde baseada num julgamento clínico sobre a falta de um impedimento ou discapacidade; normalidade como visão utópica considerada a partir do que se valoriza numa dada cultura ou sociedade; normalidade como transação definida a partir da maneira como um indivíduo influencia e é influenciado por outros.

A terceira etapa que se está propondo, acrescenta um novo processo de categorização dentro da própria amostra inicialmente

Movimento, Porto Alegre, v. 15, n. 03, p. 293-313, julho/setembro de 2009. 


\section{Ensaios Luis E.B.P.T. Dantas, Edison de Jesus Manoel}

identificada através das duas etapas anteriores; agora para selecionar sujeitos para fins de pesquisa. Essa terceira etapa consiste em subclassificar os indivíduos, mas, agora, em relação aos seus déficits particulares, tendo como referência os processos subjacentes à ação motora. Isto é, busca-se formular uma deficiência ou algumas deficiências que teriam como consequência as incapacidades descritas para o TDC. Nessa formulação, também levantam-se hipóteses sobre as possíveis patologias envolvidas. Um construto que poderia ser empregado nessa etapa advém da abordagem modular. Essa abordagem decorre da proposição clássica de Fodor (1975) segundo a qual o cérebro, em seu processo evolutivo, teria sido composto a partir de módulos relativamente estáveis que desempenhariam funções específicas e de forma independente. Um módulo não interfere no funcionamento do outro e se desenvolveriam de forma independente.

Um exemplo de abordagem modular nas ações motoras refere-se ao trabalho de Jones (1993) que preconiza pelo menos três módulos de processamento subjacentes à ação motora: organização temporal, controle da força, sequenciamento motor. O módulo de organização temporal compreende dois tipos de estabelecimento de timing. O primeiro referente a quando os elementos que constituem uma ação devem ocorrer entre si. O segundo refere-se ao timing da ação em relação ao timing de eventos externos ao indivíduo. O módulo de controle de força envolveria a capacidade de calibração da ativação do sistema muscular no emprego de esforço para se deslocar e principalmente manipular objetos. O módulo de sequenciamento consistiria na organização dos elementos da ação num plano hierarquicamente organizado (elementos simples compondo elementos complexos) e sua ordenação considerando os eventos necessários à consecução de uma ação. Por exemplo, para abrir uma porta, a criança necessita compreender que a tarefa envolve rotação da maçaneta no sentido anti-horário seguida do deslocamento da porta na direção do seu corpo. Esses eventos traduzir-se-ão em movimentos corporais diversos. A rotação da maçaneta pode ser efetuada por um movimento de supinação da mão esquerda ou de pronação da mão direita. Em cada caso, o deslocamento da porta poderá ser realizado com a flexão do cotovelo e abdução do braço, se com a mão esquerda, ou

Movimento, Porto Alegre, v. 15, n. 03, p. 293-313, julho/setembro de 2009. 
com flexão do cotovelo com fixação do braço abduzido acompanhado da rotação do tronco no sentido horário, se com a mão direita. O modelo modular tem se mostrado empiricamente válido (PIEK; SKINNER, 1999; SVEISTRUP; BURTNER; WOOLLACOTT, 1992; WILLIAMS; WOOLLACOTT; IVRY, 1992; LUNDYEKMAN; IVRY; KEELE; WOOLLACOTT, 1991). Na direção de justificar e fortalecer uma avaliação modular, cabe destacar que é comum observar crianças identificadas com TDC apresentarem déficits diferentes entre si. Algumas têm dificuldades em tarefas de locomoção, outras em tarefas de manipulação com objetos em movimento e outras ainda têm dificuldade em tarefas que envolvem a combinação de ações diferentes como locomoção com manipulação. Um dos desafios dentro da avaliação modular é o de selecionar as tarefas representativas de cada módulo. Em outro trabalho, buscou-se caracterizar a organização temporal para investigar os possíveis déficits nesse módulo em crianças com TDC (DANTAS, 2006). Neste trabalho, buscou-se desenvolver as tarefas que abarcariam todas as funções da organização temporal como estabelecimento e manutenção de um ritmo preferido/confortável; percepção de ritmo (originário de eventos externos) e capacidade de reproduzi-lo com movimentos, sincronização do ritmo pessoal com um ritmo externamente estabelecido; coincidência temporal entre um evento pessoal (uma ação de tocar um alvo) com um evento externo (a queda de uma bola num alvo). Trata-se de um trabalho de taxonomia da organização temporal nas ações motoras. A construção dessas taxonomias é uma etapa fundamental para tornar mais robusta a avaliação modular. Há muito o que fazer não só na direção de tornar consistente a taxonomia da organização temporal, mas também na direção de construir taxonomias para os módulos de força e sequenciamento.

A partir do repertório de incapacidades apresentadas por indivíduos diagnosticados como sendo portadores de TDC, encontram-se evidências de déficits ou deficiências nos três módulos. Do ponto de vista anatômico e estrutural, esses módulos encontram-se associados da seguinte forma: Módulo de organização temporal - cerebelo; Módulo de controle de força - gânglios de base; Módulo de sequenciamento - córtex motor (SVEISTRUP; BURTNER; WOOLLACOTT,

Movimento, Porto Alegre, v. 15, n. 03, p. 293-313, julho/setembro de 2009. 
1992). Com essa associação, pode-se proceder a uma investigação minuciosa do lócus de possíveis danos estruturais que caracterizariam o nível da patologia.

Caso fossem adotados esses procedimentos, futuros estudos deveriam buscar inicialmente identificar crianças com dificuldades motoras através da aplicação de um teste motor e da análise do comportamento da criança no seu cotidiano. A existência ou não de impacto da condição motora sobre a vida cotidiana da criança (através de questionário, entrevista e observação direta) seria de particular interesse nessa orientação. A seguir, o diagnóstico da criança com TDC se daria com base nos critérios já existentes e prescritos pelo manual da APA - DSM - IV (2002). Com a amostra de TDC identificada, passa-se à caracterização das dificuldades com a finalidade de enquadrar os indivíduos nos chamados subtipos de TDC, como tem sido proposto por vários estudos (SUGDEN; WRIGHT, 1998; HOARE, 1994; DEWEY; KAPLAN, 1994; MACNAB, MILLER; POLATJKO, 2001). A identificação dos subtipos corresponde à terceira etapa preconizada no presente ensaio. Está-se propondo que se dê destaque a subtipos com base na abordagem modular, porque ela forneceria subsídios para uma investigação teórica, isto é, sobre os mecanismos subjacentes à condição TDC. Assim, na última etapa, dentro da amostra diagnosticada como portadora de TDC, formaríamos subgrupos (ou clusters), por exemplo, com aqueles indivíduos que apresentam como característica marcante, dificuldades em tarefas com demanda temporal. Essa diferenciação serve para ressaltar a complexidade envolvida na categorização de transtornos, denotando que a dificuldade maior no estudo de transtornos do desenvolvimento pode estar residindo na etapa de conceituação do que eles são.

A proposição da terceira etapa poderá conduzir a avanços nas questões "por que é?" (natureza do problema) e "quais as possibilidades" (intervenção) com relação ao TDC. Essas questões se refeririam não ao indivíduo com TDC, mas àqueles com TDC que mostram problemas na organização temporal do movimento (timing). A objetividade dessa categorização possibilitaria um ganho na homogeneidade da amostra que é uma condição básica para o sucesso nas investigações de natureza causal e para proposição de programas de intervenção mais eficientes.

Movimento, Porto Alegre, v. 15, n. 03, p. 293-313, julho/setembro de 2009. 


\section{CONSIDERAÇÕES FINAIS}

O TDC caracteriza-se por uma deficiência na função motora que, até o momento, não é associada a nenhuma anormalidade conhecida da estrutura neuroanatômica, fisiológica. Ele pode ser diagnosticado pela identificação das dificuldades comportamentais (incapacidades) em demandas motoras típicas como atividades de vida diária e de lazer. Em função dessa incapacidade, o TDC tem como consequência uma manifesta desvantagem para o exercício de atividades do cotidiano e na escola. No presente ensaio, formulou-se uma crítica ao raciocínio hoje frequente que diagnostica e identifica indivíduos para pesquisa com base nas incapacidades (obtida pela aplicação de testes normativos como teste $\mathrm{MABC}$ ) e desvantagens (com base na lista de checagem do mesmo teste e preenchida por professores e pais). Esse procedimento tem levado a uma grande heterogeneidade de deficiências associadas ao TDC. A profusão de deficiência, longe de indicar um transtorno complexo, pode estar refletindo imprecisões de natureza metodológica e conceitual. A proposta é que se pense em duas possibilidades. Na primeira, busca-se subdividir os indivíduos em grupos por incapacidade específica, de maneira a se chegar a uma deficiência associada por raciocínio indutivo. Na segunda possibilidade, propõese subdividir os indivíduos por deficiência usando de um construto teórico conhecido como abordagem modular. Dessa forma, o TDC poderia ser entendido a partir de um raciocínio dedutivo, isto é, com base em hipóteses sobre como funcionam os módulos, estabelecerse-iam tarefas e condições experimentais que testariam a integridade de cada módulo.

Por último, cabe uma palavra sobre a intervenção. O trabalho de profissionais preocupados em melhorar a condição de vida de indivíduos com transtornos se depara com o fato de que os sistemas de classificação de deficiências dão destaque às incapacidades dos indivíduos ao invés de explorarem suas potencialidades e competências (MANOEL, 1986; 1996). Assim, a finalidade de uma intervenção em indivíduos com TDC consistiria na diminuição das desvantagens que o indivíduo enfrenta na condução de sua vida no ambiente social. Ou seja, o programa de intervenção deve procurar meios

Movimento, Porto Alegre, v. 15, n. 03, p. 293-313, julho/setembro de 2009. 
sociais (ambiente), individuais (intencionalidade) e relacionados às demandas impostas, ajudar o indivíduo a superar as desvantagens derivadas das incapacidades. Em síntese, esse programa teria como foco ajudar o indivíduo a explorar a flexibilidade presente na relação entre os movimentos e os objetivos ambientais que caracterizam toda ação motora.

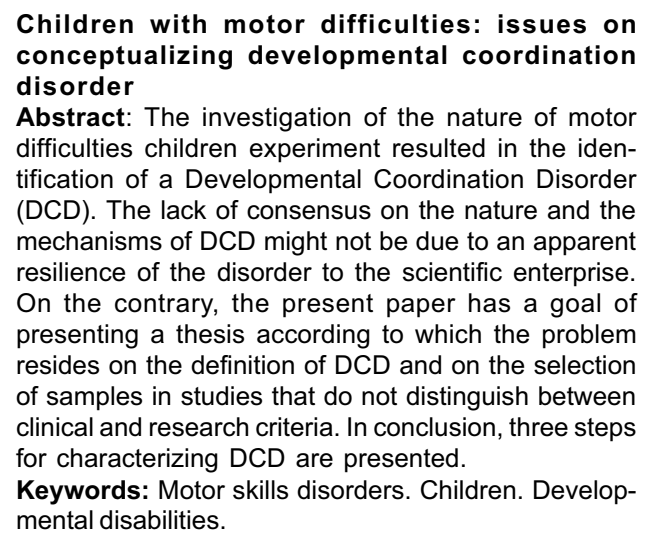

Niños con dificultad motoras: cuestiones en el concepto del trastorno del desarrollo de la coordinación

Resumen: La investigación de la naturaleza de las dificultades motrices experimentadas por los niños ha resultado en la identificación de Trastorno del Desarrollo de la Coordinación (TDC). La falta de un acuerdo acerca de la naturaleza y mecanismos del TDC puede no ser riestrita a una aparente resistencia del trastorno a las investigaciones científicas. El presente artículo postula la tesis de que el problema esta en la definición acerca del entendimiento del TDC y en la selección de las populación en estudios que no distinguen el uso de criterios clínicos de los criterios de investigación científica. La caracterización del TDC se presenta en tres etapas.

Palabras clave: Trastornos dela destreza motora. Niño. Discapacidades del desarrollo.

Movimento, Porto Alegre, v. 15, n. 03, p. 293-313, julho/setembro de 2009. 


\section{REFERÊNCIAS}

AMIRALIAN, M. L.T., PINTO, E. B., GHIRARDI, M. I.G., LICHTIG, I., MASINI, E. F.S.; PASQUALIN, L. Conceituando deficiência. Revista de Saúde Pública, São Paulo, v.34, n.1, p. $97-103,2000$

ANELL. A.L. Proceedings of the International Psychotherapeutics. Leyden: 1951.

ANELL. A.L. Motor disorders at school. Berne: Seelische Gesundbei, 1959.

ASSOCIAÇÃO PSIQUIÁTRICA AMERICANA. DSM-IV: Manual diagnóstico e estatístico de transtornos mentais: DSM-IV. Coord. Miguel Jorge. Tradução de Dayse Batista Porto Alegre: Artes Médicas, 2002. p. 49-50.

BERNSTEIN, N.A. On dexterity and its development. In: LATASH, M.L.; TURVEY, M.T. (Eds.). Dexterity and its development. Mahawa: LEA, 1996.

BRUNER, J. S. Acts of meaning. Harvard: Harvard University, 1990.

CANNETI, E. (1935). Auto de fé. Rio de Janeiro: Nova Fronteira, 1982. p. 155.

CERMAK, S.; GUBBAY, S.; LARKIN, D. What is developmental coordination disorder? In: CERMARK, S.A.; LARKIN, D. Development coordination disorder. Columbia Circle: Delmar, p. 2-22, 2002.

CLUMSY children. British Medical Journal, London, v.22, p. 1665-1666. (Editorial), 1962.

DANTAS, L. E. P. T. Perfil de crianças com transtorno do desenvolvimento da coordenação em tarefas de timing. Tese (Doutorado). Escola de Educação Física e Esporte, 137 folhas, São Paulo: Universidade de São Paulo, 2006.

DEWEY, D.; KAPLAN, B. J. Subtyping of developmental motor deficits. Developmental Neuropsychology, Mahwah, v. 10, n. 3, p. 265-284, 1994.

GEUZE, R.; JONGMANS, M.J.; SCHOEMAKER, M.; SMITS-ENGELSMAN, B. C. Clinical and research diagnostic criteria for developmental coordination disorder: a review and discussion. Human Movement Science, Amsterdam, v. 20, p. 7-47, 2001.

HAHN, U.; CHARTER, N. Concepts and similitary. In: LAMBERTS, K.; SHANKS, D. (Eds.). Knowledge, Conceps, and categories. Cambridge: MIT, 1997. p. 43-92.

HOPKINS, B. Developmental disorders: An action based account. In: VALSINER, J.: CONNOLLY, K.J. (EDS.), Handbook of developmental psychology. London: Sage Publications, 2005. p. 292-332.

HOARE, D. Subtypes of developmental coordination disorder. Adapted Physical Activity Quarterly, Champaign, v. 11, p. 158-169, 1994.

HULME, C.; LORD, R. Clumsy children: a review of recent research. Child Care, Health, and Development, London, v. 12, p. 257-269, 1986.

Movimento, Porto Alegre, v. 15, n. 03, p. 293-313, julho/setembro de 2009. 
JONES, S. K. A modular approach to individual differences in skill and coordination. In: Starkes, J. L.; and Allard, F. Cognitive issues in motor expertise. Amsterdan: Elsevier Science, p.273-293, 1993.

LACEY, H. Valores e atividade científica. São Paulo: Discurso Editorial, 1998.

LAMBERTS, K.; SHANKS, D. Knowledge, Conceps, and categories. Cambridge: MIT, 1997.

LOSSE, A.; HENDERSON, S.; ELLIMAN, D.; HALL, D.; KNIGHT, E.; JONGAMANS, M. Clumsiness in children: Do they grow out of it? A ten-year follow-up study. Developmental Medicine and Child Neurology, London, v. 33, p. 55-68, 1991.

LUNDY-EKMAN, L.; IVRY, R.; Keele, S.; Woollacott, M. Timing and force control deficits in clumsy children. Journal of Cognitive Neuroscience, Cambridge, $v$. 3, n. 4, p. 367-376, 1991.

MACNAB, J. J.; MILLER, L. T.; POLATAJKO, H. J. The search for subtypes of DCD: Is cluster analysis the answer? Human Movement Science, Amsterdam, v. 20, n. 1/2, p. 49-72, 2001.

MANOEL, E. de J. A importância da abordagem desenvolvimentista na educação física adaptada. Boletim da Federação Internacional de Educação Física, Foz de Iguaçu, v.57, n.2, p. 5-9, 1987.

MANOEL, E. de J. O estudo do comportamento motor da pessoa portadora de deficiência: problemas e questões. Revista Brasileira de Saúde Escolar, Campinas, v. 4, n. 3 / 4, p. 11-21, 1996.

OFFER. D.; SABSHIN, M. Normality: theoretical and clinical concepts of mental health. New York: Basic, 1974.

ORGANIZAÇÃO MUNDIAL DA SAÚDE. Classificação de transtornos mentais e de comportamento da CID - 10: descrições clínicas e diretrizes diagnósticas. Porto Alegre: Artes Médicas, p. 245, 1993.

ORTON, S.T. Reading, writing and speech problems and children. New York: Norton, 1937.

PIEK, J. P.; SKINNER, R. A. Timing and force control during a sequential tapping task in children with and without motor coordination problems. Journal of the International Neuropsychology Society, New York, v. 5, p. 320-329, 1999.

PRECHTL, H.F.R.;STEMMER, J.C. Developmental Medicine and Child Neurology, London, v.2, p. 119, (Editorial), 1962.

RISPEN, J.; VAN YPEREN, T.A. The role of SDD in classification systems: historical overview and current status. In: RISPENS, J.; VAN YEPEREN, T. A.; YULE, W. (Eds.). Perspectives on the classification of special developmental disorders. Dordrecht: Kluwer Academic, 1998. p. 15-37.

Movimento, Porto Alegre, v. 15, n. 03, p. 293-313, julho/setembro de 2009. 
SUGDEN, D.A.; WRIGHT, H. Motor coordination disorders in children. Thousand Oaks: Sage, 1998.

WALTON, J.N.; ELLIS, E.; COURT, S.D.M. Clumsy children: developmental apraxia and agnosia. Brain: Oxford, n.85, p. 603, 1962.

WILLIAMS, H. G.; WOOLLACOTT, M. H.; IVRY, R. Timing and motor control in clumsy children. Journal of Motor Behavior, Washington, v. 2, p. 165-172, 1992.

WRIGHT, H. C.; SUGDEN, D. A. A two step procedure for the identification of children with developmental co-ordination disorder in Singapore. Developmental Medicine and Child Neurology, London, v. 38, p. 1099-1105, 1996

Recebido em: 08.05.2008

Aprovado em: 25.03. 2009

Movimento, Porto Alegre, v. 15, n. 03, p. 293-313, julho/setembro de 2009. 